\title{
BMJ Open Residential status and health in middle and late life: a population-based study with new data from Spain
}

\author{
Miguel Requena (i) , ${ }^{1}$ David Reher (1) ${ }^{2}$
}

To cite: Requena M, Reher D. Residential status and health in middle and late life: a population-based study with new data from Spain. BMJ Open 2020;10:e033330. doi:10.1136/ bmjopen-2019-033330

- Prepublication history for this paper is available online. To view these files, please visit the journal online (http://dx.doi. org/10.1136/bmjopen-2019033330).

Received 31 July 2019 Revised 27 December 2019 Accepted 15 January 2020

\section{Check for updates}

(c) Author(s) (or their employer(s)) 2020. Re-use permitted under CC BY-NC. No commercial re-use. See rights and permissions. Published by BMJ.

${ }^{1}$ Sociologia II, Universidad Nacional de Educacion a Distancia, Madrid, Spain ${ }^{2}$ Sociologia Aplicada, Universidad Complutense de Madrid, Madrid, Spain

Correspondence to Dr Miguel Requena; mrequena@poli.uned.es

\section{ABSTRACT}

Objectives To address how different residential situations impact the likelihood of death among mature adults and elderly persons.

Design Population-based study with administrative data linked to census data.

\section{Setting Spain.}

Participants Spanish population alive on 1 January 2012, observed between 1 January 2012 and 31 December 2012. A 10\% random sample of the Spanish population, including 2054427 person years and 28736 deaths, is used.

Main outcome measure Registered deaths in the 2012 Spanish vital statistics.

Methods Using a new data set based on linked administrative registers, we estimate unadjusted and adjusted mortality rates by coresidential situation. Differential mortality is measured by rate ratios (RR) estimated with Poisson regression. Cause of death data are used to explore the mechanisms involved in excess mortality by residential status.

Results Compared with men 45-54 living with partners, the risk of death is much higher for those without partners living with others (RR 2.0,95\% $\mathrm{Cl} 1.7$ to 2.4) or for those living alone (RR $1.9,95 \% \mathrm{Cl} 1.5$ to 2.4 ). After 84 , excess mortality among men living with others persists (RR 1.4, $95 \% \mathrm{Cl} 1.3$ to 1.5$)$, but disappears for those living alone (RR $1.0,95 \% \mathrm{Cl} 0.9$ to 1.1). Both among women 45-64 living with others but without partner (RR 1.8, 95\% Cl 1.5 to 2.3 ) and among those living alone (RR $2.2,95 \% \mathrm{Cl} 1.5$ to $3.1)$ the pattern is similar to men. At higher ages, however, excess mortality for women living alone decreases (RR 1.2, $95 \% \mathrm{Cl} 1.1$ to 1.2 ), though it persists for women living with others (RR $1.9,95 \% \mathrm{Cl} 1.7$ to 2.0 ).

Conclusions These findings indicate direct effects of living arrangements on mortality and health-related selection effects influencing residential choices. These effects may be partially affected by age and prevailing societal and cultural contexts.

\section{INTRODUCTION}

In recent decades, living arrangements of older and mature adults have experienced important changes in developed world. ${ }^{1}$ The importance of persons living alone has grown substantially and today represents an important percentage of the elderly: $35 \%-45 \%$ of women and $15 \%-25 \%$ of all men

\section{Strengths and limitations of this study}

There are few studies in which residential status is related specifically to the likelihood of death.

- This study is based on a nationally representative sample of the Spanish population obtained by linking individual data from vital statistics, municipal registers, and the 2011 census that affords a high degree of precision in estimates.

- Given the observational research design used, only statistical associations can be observed and hence strong causal claims are not strictly proven.

- Since change over time in the main exposures cannot be observed, only deaths occurring in 2012 are considered in the analysis.

- Although the use of cause of death data helps illustrate the role of specific mechanisms behind differential mortality by residential status, the actual number of deaths for different causes by age and sex in our sample is often relatively small, thus limiting the scope of our analysis.

above $65^{2-5}$; living alone during the mature adult years also has grown, now including $10 \%-20 \%$ of people aged $50 .{ }^{6}$ Living alone is considered a relevant characteristic of contemporary developed societies. The share of partnered people in these age groups has shown divergent trends with increases among the elderly, thanks largely to longer spousal survival, and decreases among adults because of the rise of divorce and declines in marriage rates during the 1980 s and 1990s. ${ }^{7}$ During mature adulthood, living with others but without partners is a relatively infrequent residential option in most developed countries. At higher ages, however, in developed societies with strong familistic traditions the prevalence of these often kin-based residential situations may increase substantially. ${ }^{8}$

The implications of these residential choices for the health and well-being among mature adults and the elderly are far from clear. It is widely held that living with a spouse has generally beneficial implications for health. With respect to mortality, the existing 
literature has yielded interesting results in which lower death rates are found among currently married people ${ }^{9-16}$ with higher ones among never-married, divorced or widowed people. ${ }^{17-21} \mathrm{~A}$ weak point of these studies is that marital status for those not currently married only reflects coresidence in an indirect way and may be less significant than people's actual living arrangements. Empirical analysis has shown ambiguous results on this matter, with studies in different countries and social settings showing either no association between residential status and mortality ${ }^{22}$ or, more generally, higher mortality among those living alone. ${ }^{23-26}$ Different results have been observed for women and men ${ }^{27-30}$ and, recently, longer survival of people living alone at older ages has been documented for Belgium. ${ }^{31}$ The mechanisms behind the residential gradients in mortality rates are not clear.

According to this literature, we should expect lower death rates for those living with spouses or partners, that is, in long-term stable relationships, often with people who are actively interested in their well-being and ready to intervene on each other's behalf. People living alone, independent of their marital status, are people who have nobody else present to help them with health issues, especially cardiovascular and catastrophic events. ${ }^{32} 33$ We can expect higher mortality among people on their own, at least as mature adults. People living with others (kin or not) will not have the same durable kin ties that characterise long-term relationships with spouses. Here coresidents may be in a position to intervene in some cases-normally catastrophic health events-but are much less likely to do so in other situations. We can expect higher mortality among them than among persons living with a stable partner.

These expectations also depend on the way health status affects residential options. ${ }^{34}$ Married people may be positively selected into marriage because of their health and persons with poor health status are more likely to be living alone. ${ }^{35}$ However, after a certain age living alone will tend to be selective for those with the best initial health. Very poor health may make living alone nearly impossible. Those with very poor health tend to be selected out of households in which they are alone and into ones where they are with other people or, in cases of severe health depletion, into certain types of institutional arrangement. The importance of this positive selection effect for living alone should grow with age, as the general health conditions of the population worsen and become increasingly important for residential choice. We hypothesise that in the absence of a spouse there should be excess mortality among those living with others, in comparison with those living alone and that this effect will be visible later in life when the positive selection for health of those living alone is highest.

There are few studies in which residential status is related specifically to the likelihood of death. ${ }^{24} 253136-40$ The specific goal of this paper is to address how living alone, living with a spouse and living with others tend to condition the survival of mature adults and elderly persons in Spain. Using cause of death data will help illustrate more precisely specific mechanisms involved. Take, for example, the case of acute myocardial infarction. The risk of death due to this type of catastrophic event will be lower among those with better baseline health. When a prior health selection effect is in place that determines coresidence, the type of living arrangement earmarked for those with poorer health will tend to be associated with higher mortality because of it. At the same time, however, the presence of others in the household, especially of spouses/partners, can limit the effects of heart attacks because they will be quicker to respond to the event itself and will be in a position to assist in the recovery process. We maintain that this role of others in the household will be more relevant when they are spouses than when they are other people, particularly non-kin. Unpacking the relative strength of these effects is impossible with population-based data, but they help us understand the way both variables can come into play, especially among older people.

\section{METHODS}

\section{Data sources and participants}

The analysis in this paper makes use of a new data set of linked administrative registers for Spain. Deaths taken from vital registers (Movimiento Natural de la Población) and household size coming from municipal register (Padrón Municipal de Habitantes, 2012 update) have been linked to data regarding the same individuals present in the 2011 census, including the individual and household characteristics present in modern censuses (sex, age, marital status, education, migratory status, country of origin, size of municipality and others). All data were provided by the Spanish national statistical office (Instituto Nacional de Estadística, INE) in separate files with the identifiers necessary for linking records.

The linked data set consists of a sample of around $10 \%$ of the population living in households present on the 2011 census. These data do not include deaths of people not present on the census, either living in institutions or living abroad. More than $96 \%$ of the deaths included in the file were successfully linked. Non-linked deaths are not affected by any relevant selection factor and there are no substantial differences between distributions of deaths (by sex, age and marital status) in the linked data and in the set of all deaths in the vital register for 2012. Our analytical sample includes 2054276 person year observations of men and women $45+$ who were alive at the beginning of 2012 and contains no identifiable bias. In the data set, 28736 of these individuals died in 2012. Table 1 presents the characteristics of this population.

\section{Variables}

All the exposure variables in this study come from the 2012 Spanish Municipal Register and the 2011 census. The primary exposure-a combination of marital status and coresidence-is coded as a straightforward trichotomous 
Table 1 Characteristics of the population under study

\begin{tabular}{|c|c|c|c|c|c|c|}
\hline & \multicolumn{6}{|l|}{ Age } \\
\hline & $45-54$ & $55-54$ & $65-74$ & $75-84$ & $85+$ & Total \\
\hline \multicolumn{7}{|l|}{ Men } \\
\hline Person years & 319570 & 258861 & 199432 & 148740 & 47213 & 973816 \\
\hline$\%$ age & 32.8 & 26.6 & 20.5 & 15.3 & 4.8 & 100 \\
\hline 2012 deaths & 718 & 1557 & 2667 & 5564 & 5158 & 15664 \\
\hline Deaths ${ }^{*} 1000$ & 2.25 & 6.01 & 13.37 & 37.41 & 109.25 & 16.09 \\
\hline \multicolumn{7}{|l|}{$\%$ coresidence } \\
\hline Living with partner & 72.8 & 78.7 & 81.2 & 76.9 & 60.7 & 76.1 \\
\hline Living with others, no partner & 19.2 & 12.5 & 8.8 & 10.8 & 22.0 & 14.1 \\
\hline Alone & 8.1 & 8.8 & 10.0 & 12.4 & 17.3 & 9.7 \\
\hline \multicolumn{7}{|l|}{$\%$ education } \\
\hline Primary education or less & 17.0 & 28.3 & 49.0 & 71.1 & 76.9 & 37.7 \\
\hline Secondary & 65.5 & 56.3 & 39.9 & 22.6 & 17.8 & 49.0 \\
\hline Tertiary & 17.5 & 15.4 & 11.1 & 6.3 & 5.3 & 13.3 \\
\hline \multicolumn{7}{|l|}{$\%$ size of municipality } \\
\hline 10000 inhabitants or less & 42.9 & 43.8 & 46.6 & 54.3 & 58.2 & 46.4 \\
\hline $10001-100000$ & 15.9 & 14.8 & 13.5 & 11.5 & 10.3 & 14.2 \\
\hline $100001-500000$ & 22.6 & 23.2 & 21.4 & 17.2 & 15.6 & 21.3 \\
\hline $501,000+$ & 18.6 & 18.3 & 18.5 & 17.0 & 15.8 & 18.1 \\
\hline \multicolumn{7}{|l|}{$\%$ migratory status } \\
\hline Natives & 92.7 & 95.8 & 96.6 & 98.1 & 98.5 & 95.4 \\
\hline Non-natives & 7.3 & 4.2 & 3.4 & 1.9 & 1.5 & 4.6 \\
\hline \multicolumn{7}{|l|}{ Women } \\
\hline Person years & 324742 & 265587 & 216087 & 191406 & 82638 & 1080459 \\
\hline$\%$ age & 30.1 & 24.6 & 20.0 & 17.7 & 7.6 & 100 \\
\hline 2012 deaths & 405 & 626 & 1224 & 3947 & 6870 & 13072 \\
\hline Deaths ${ }^{*} 1000$ & 1.25 & 2.36 & 5.66 & 20.62 & 83.13 & 12.10 \\
\hline \multicolumn{7}{|l|}{$\%$ coresidence } \\
\hline Living with partner & 73.8 & 74.3 & 67.7 & 46.2 & 18.5 & 63.6 \\
\hline Living with others, no partner & 21.0 & 16.4 & 15.3 & 23.6 & 44.4 & 21.0 \\
\hline Alone & 5.2 & 9.3 & 17.0 & 30.3 & 37.1 & 15.5 \\
\hline \multicolumn{7}{|l|}{$\%$ education } \\
\hline Primary education or less & 16.0 & 33.1 & 58.9 & 78.6 & 83.4 & 45.0 \\
\hline Secondary & 62.8 & 53.5 & 34.6 & 18.4 & 14.1 & 43.3 \\
\hline Tertiary & 21.2 & 13.4 & 6.5 & 3.1 & 2.6 & 11.7 \\
\hline \multicolumn{7}{|l|}{$\%$ size of municipality } \\
\hline 10000 inhabitants or less & 38.6 & 38.6 & 43.1 & 50.2 & 51.4 & 42.5 \\
\hline $10001-100000$ & 16.3 & 15.0 & 13.5 & 11.7 & 10.8 & 14.2 \\
\hline $100001-500000$ & 24.6 & 25.3 & 22.3 & 18.6 & 17.9 & 22.7 \\
\hline $501,000+$ & 20.6 & 21.2 & 21.1 & 19.5 & 19.9 & 20.6 \\
\hline \multicolumn{7}{|l|}{$\%$ migratory status } \\
\hline Natives & 91.7 & 94.6 & 96.3 & 98.3 & 98.5 & 95.0 \\
\hline Non-natives & 8.3 & 5.4 & 3.7 & 1.7 & 1.5 & 5.0 \\
\hline
\end{tabular}


variable (living with a partner/living with others but without a partner/living alone). Potential confounders are sex, age (coded into five 10-year intervals from 45 to 54 to $85+$ ), and educational attainment, a proxy for socioeconomic status, based on the International Standard Classification of Education (ISCED) (ordered into three levels: primary education or less (ISCED $=0,1$ ), secondary education (ISCED $=2,3,4$ ) and tertiary education (ISCED $=5,6,7,8$ ). Size of municipality (four categories: $\leq 10000,10001-100000,100001-500000000$ and $501000+$ ) and migratory status (natives and non-natives) are included as population controls.

The main outcome variable are the registered deaths in the 2012 Spanish vital statistics. Causes of death have been classified from the Spanish INE adaptation of the International Statistical Classification of Diseases (10th revision) into four categories: (i) infectious, endocrine and chronic diseases (codes A00 to B99, D50 to D89, E00 to E90, F00 to F09, F20 to F29, G00 to G83, H00 to H95, J00 to J99, K00 to K93, L00 to L99, M00 to M99, N00 to N77, O00 to O99, Q10 to Q18, Q30 to Q99; R00 to R99, Y35 to Y98, Z00 to Z99, U00 to U85); (ii) cancer and tumours (codes C00 to D48); (iii) diseases of the circulatory system (I00 to I99, Q20 to Q28); and (iv) mental diseases, suicides, accidents and other external causes (F10 to F19, G90 to G99, Q00 to Q07, S00 to T98, V01 to Y09).

\section{Statistical methods}

A three-step analytical strategy is used in this paper. First, we cross-tabulate 2012 deaths and persons by sex, age and residential status (partnered/with others/alone), calculate death rates and estimate corresponding rate ratios (RR). The denominators for the rates are based on the population present in the census. Second, in order to refine the analysis and control for possible confounders RR are estimated by means of multivariate log-linear Poisson regression models with cells as the unit of analysis and living with a partner as the baseline. After stratifying by sex and broad age category, we adjusted ratios for age, educational attainment, size of municipality and migratory status.

Finally, we look at mortality differentials by coresidential status for each of four groups of cause of death. These data enable us to explore mechanisms involved in any differential mortality, but the scope of this part of the analysis is limited by the actual number of deaths for different causes. The indicators generated are the ratios between cause-specific death rates for people in different coresidential situations, with partnered people as the baseline. Poisson regression models are used, but this time we stratify the analysis for two larger age intervals: 45-64 and 65+.

\section{Patient and public involvement}

No patient involved.
RESULTS

Table 1 shows 2012 period prevalence rates of living with a partner, living with others and living alone by age and provides a useful background for the results presented here. During the mature adult years, differences in the incidence of living alone by sex are relatively small, oscillating around $10 \%$. After 65 , rates of living alone among women skyrocket, reaching $37 \%$ in later life. For men, there is also an increase, but it is much more gradual and never much above $20 \%$. About three quarters of mature adults live with a spouse or partner and levels are higher among males. Living with others but no partner is more frequent among women, and in both cases is higher among people under 55 and over 75 years of age.

Mortality rates and their respective ratios (table 2) point to a clear mortality/coresidence pattern associated with age. Living with others leads to higher mortality than for those with partners at most ages. Relative differences decline substantially with age among men but not among women. Between 45 and 54, differences among men $(\mathrm{RR}=2.03,95 \% \mathrm{CI} 1.72$ to 2.40$)$ are similar to women ( $\mathrm{RR}=1.82,95 \% \mathrm{CI} 1.45$ to 2.26$)$, while in later life $(85+)$ the excess mortality for women living with others $(\mathrm{RR}=1.87,95 \% \mathrm{CI} 1.74$ to 2.01$)$ is far greater than it is for men $(\mathrm{RR}=1.39,95 \% \mathrm{CI} 1.31$ to 1.49$)$. The pattern for those living alone is different in comparison to those with partners, although here too differences also decline with age. Among mature adults 45-64 for men ( $R R=1.91$, $95 \%$ CI 1.50 to 2.42$)$ and for women ( $R R=2.21,95 \%$ CI 1.53 to 3.12 ), there is differential mortality among those living alone. However, among men living alone after 75 ( $\mathrm{RR}=1.04,95 \%$ CI 0.96 to 1.13 for $75-84$; $\mathrm{RR}=1.00,95 \%$ CI 0.92 to 1.08 for $85+)$ and women above $65(\mathrm{RR}=0.97$, $95 \%$ CI 0.82 to 1.14 for $65-74 ; \mathrm{RR}=1.00,95 \%$ CI 0.93 to 1.09 for $75-84$; RR=1.15, $95 \%$ CI 1.06 to 1.24 for $85+$ ) excess mortality disappears.

When adjusting for possible confounders (age, educational attainment, size of municipality and migratory status) results are similar to those derived from unadjusted ratios (figure 1). The excess mortality of those living with others is visible at all ages, but tends to diminish after 54 for men and after 64 for women, when the ratios stabilise around $1.4(\mathrm{RR}=1.41,95 \%$ CI 1.23 to 1.63 for $65-74$; $\mathrm{RR}=1.39,95 \%$ CI 1.29 to 1.49 for $75-84$; $\mathrm{RR}=1.44,95 \%$ CI 1.33 to 1.55 for $85+$ ). These adjusted ratios also show that the relative disadvantage of those living alone disappears entirely as people move from maturity to old age, though this change takes place at a later age among men ( $\mathrm{RR}=1.00,95 \%$ CI 0.92 to 1.08 for $75-84)$ than among women ( $\mathrm{RR}=0.90,95 \%$ CI 0.77 to 1.06 for $65-74)$.

The relative mortality for different types of cause of death (table 3 ) adds relevant information to the analysis. For mature adult women under 65, death rates for all causes are much higher among women living with others. Mental diseases, suicides and accidents $(\mathrm{RR}=2.94,95 \% \mathrm{CI}$ 1.50 to 5.74$)$, chronic illness ( $R R=2.22,95 \%$ CI 1.61 to 3.04 ) and circulatory diseases ( $R R=1.86,95 \%$ CI 1.26 to $2.75)$ stand out in that order. For cancer ( $R R=1.47,95 \%$ 
Table 2 Person year, deaths and mortality rates (per 1000) by coresidential status, sex and broad age groups. Relative mortality to those living with a partner expressed as RR

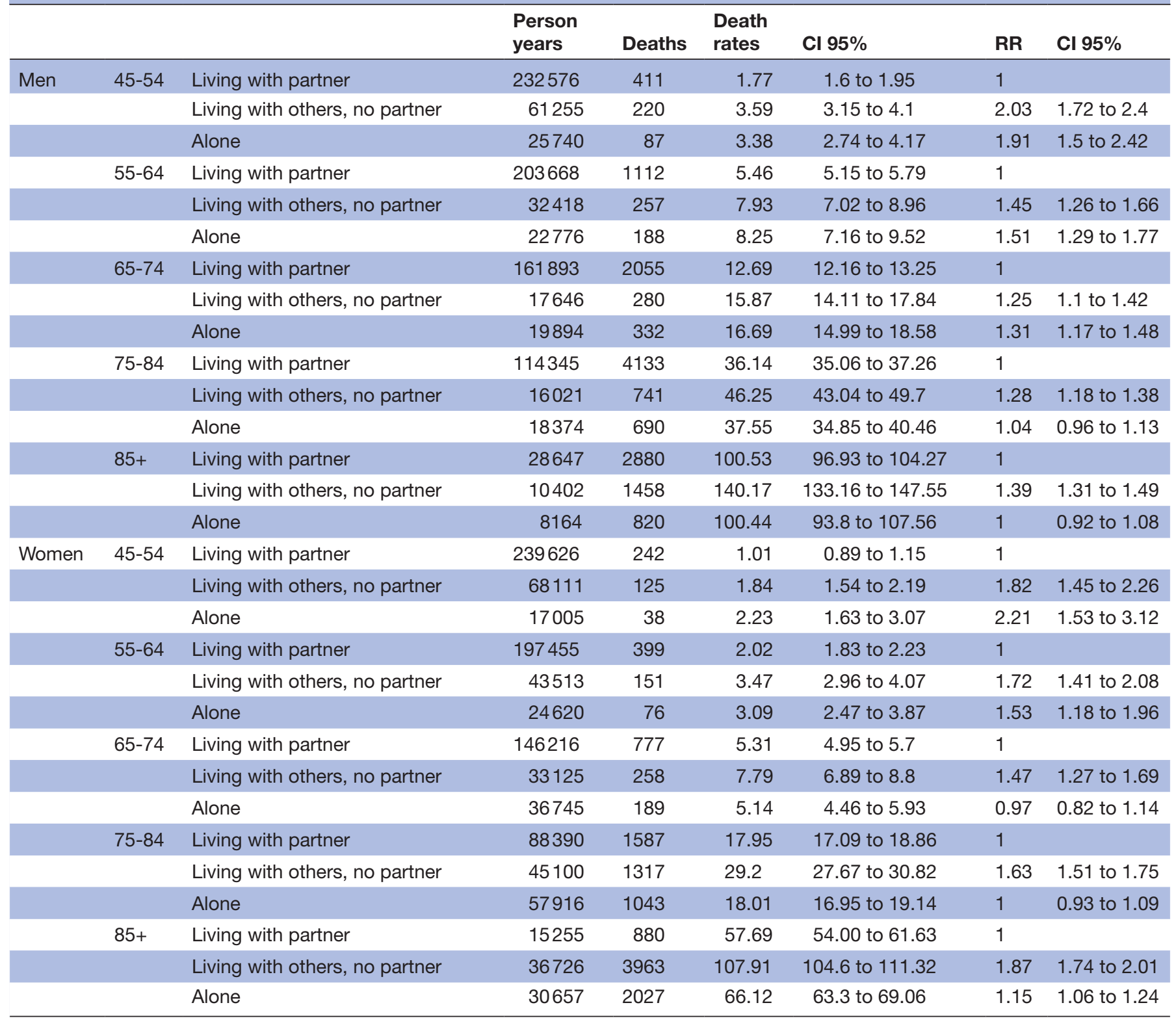

$\mathrm{RR}$, rate ratios.

CI 1.23 to 1.76 ) excess mortality is lower, but continues to exist. The pattern observed among women living alone at these ages shows excess mortality due to mental diseases, suicides and accidents $(\mathrm{RR}=4.73,95 \%$ CI 2.15 to 10.38$)$ and circulatory diseases $(\mathrm{RR}=4.64,95 \% \mathrm{CI}$ 4.31 to 5.00$)$ that is noticeably higher than for chronic diseases $(\mathrm{RR}=1.78,95 \%$ CI 1.08 to 2.94$)$ and cancer and tumours ( $R R=1.42,95 \%$ CI 1.08 to 1.86). Above 65 , excess mortality among women living with others continues to be visible for mental diseases, suicides and accidents ( $R R=3.49,95 \%$ CI 2.75 to 4.42 ) and, above all, for circulatory diseases $(\mathrm{RR}=3.77,95 \%$ CI 2.45 to 5.80$)$ and for chronic diseases ( $\mathrm{RR}=4.51,95 \% \mathrm{CI} 4.20$ to 4.85$)$. Once again, the excess mortality of these women due to tumours and cancer is considerably lower $(\mathrm{RR}=1.92,95 \%$
CI 1.75 to 2.10$)$. Among elderly women $65+$ living alone there is excess mortality for circulatory diseases $(\mathrm{RR}=2.58$, 95\% CI 2.38 to 2.79), for mental diseases, suicides and accidents ( $\mathrm{RR}=2.26,95 \%$ CI 1.75 to 2.92$)$ and for chronic diseases ( $R R=1.97,95 \%$ CI 1.81 to 2.15$)$. Once again, deaths due to tumours and cancer show lower levels of excess mortality than other groups of causes $(\mathrm{RR}=1.42$, $95 \%$ CI 1.29 to 1.56$)$.

Among mature adult males, excess mortality for those living with others is highest for mental diseases, suicides and accidents ( $R R=2.69,95 \%$ CI 1.86 to 3.88) and for infectious, endocrine and chronic illnesses ( $R R=2.60,95 \%$ CI 2.10 to 3.22), while for circulatory diseases ( $R R=1.29$, $95 \%$ CI 1.03 to 1.63 ) and cancer ( $R R=1.10,95 \%$ CI 0.09 to 1.28$)$ it is much lower. For adult men living alone the 


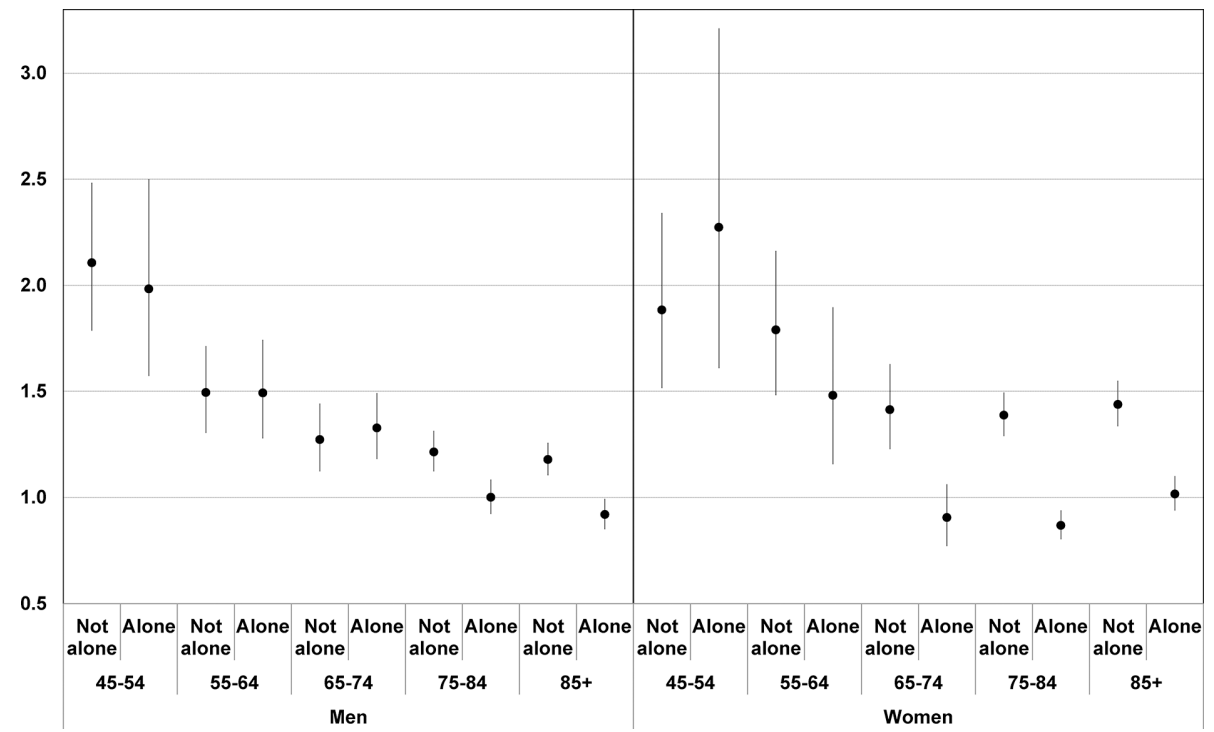

Figure 1 Mortality rate ratios (RR) (living with partner, living with others, living alone) adjusted by age, educational attainment, size of municipality and migratory status. Reference category $(R R=1)$ is for people living with partners.

pattern is similar, with mental diseases, suicides and accidents ( $\mathrm{RR}=3.00,95 \%$ CI 1.92 to 4.67$)$ and endocrine and chronic illnesses ( $\mathrm{RR}=2.76,95 \%$ CI 2.12 to 3.58) exhibiting the highest relative mortality. Among elderly men $(65+)$, deaths due to cancer $(\mathrm{RR}=1.20,95 \%$ CI 1.10 to 1.31 ) show practically no excess mortality, while for mental diseases, suicides and accidents $(\mathrm{RR}=1.91,95 \%$ CI 1.48 to 2.46 ), circulatory diseases ( $R R=2.30,95 \%$ CI 2.13 to 2.49 ) and chronic diseases ( $\mathrm{RR}=2.29,95 \%$ CI 2.13 to 2.46) excess mortality is much higher. Among men over 65 living alone, the highest excess mortality is due to mental diseases, suicides and accidents ( $\mathrm{RR}=1.88,95 \%$ CI 1.46 to 2.41 ).

In figure 2, the relative mortality for each coresidential status and group of causes is adjusted for age, education, size of municipality and migratory status. Adjusted ratios for different residential situations tend to confirm results previously obtained from unadjusted estimates. In the 45-64 age interval, excess mortality is due to infectious, endocrine and chronic illnesses, circulatory system diseases, and mental diseases, suicide and accidents-but not to cancer-among both women and men. At more advanced ages $(65+)$ virtually all disadvantages affect women and men living with others (without a partner), except for deaths caused by mental diseases, suicides and accidents among men ( $\mathrm{RR}=1.42,95 \%$ CI 1.10 to 1.82$)$.

\section{DISCUSSION}

While other studies ${ }^{34}{ }^{41-44}$ focus on how selection into marriage of those with better health or how marriage itself protects against the risk of death, producing lower death rates among married people, this paper emphasises the positive selection effect of good health among those living alone at older ages. While mature adults living alone or those living with others constitute vulnerable subpopulations in comparison to those living with spouses, at higher ages this is much less the case. For men past 75 years of age and for women past 65 there is no differential mortality for those living alone. When those living alone begin to experience serious health problems, these results suggest that people tend to move in with others and eventually die in these situations. In fact, living alone among those who are seriously ill is unlikely, especially if one has the chance to live with others. For people living with others, the importance of differential mortality declines with age, though it never disappears entirely and, among women, levels of excess mortality remain near $40 \%$ above those for women with spouses. This dual pattern associated with age points to the existence of (i) direct effects of living arrangements on mortality through which living with a partner decreases the risk of death while living alone tends to increase it; and (ii) health-related selection effects on differential living arrangements whereby people with no spouse who have better health tend to be selected into living alone and those with worse health tend to be selected into living with others. ${ }^{45}$

Cause of death data illustrate the basic mechanisms involved and how they change with age. As expected, deaths due to cancer and other tumours are basically the same for people of different residential status, regardless of their age. For mature adults 45-64, patterns for both men and women are similar. Higher levels for people living with others in comparison with those living alone are found with endocrine and chronic diseases, but not for other causes. In the case of circulatory diseases and deaths due to mental problems and accidents, the opposite is true with excess mortality higher among those living alone. This suggests that living alone may be more harmful for a person's health when catastrophic health events occur (acute circulatory problems, suicides, accidents ${ }^{30}$ ), though with processes related to chronic disease this does not happen. In later life $(65+)$, the 
Table 3 Number of deaths, unadjusted mortality rates (per thousands) by sex, broad age group and coresidential status for four groups of causes of death. relative mortality expressed as rate ratios

\begin{tabular}{|c|c|c|c|c|c|c|c|c|}
\hline \multirow{2}{*}{ Number of deaths } & & \multicolumn{2}{|l|}{ Men } & & \multicolumn{2}{|c|}{ Women } \\
\hline & & & & $45-54$ & $65+$ & $45-5$ & & $65+$ \\
\hline \multicolumn{9}{|l|}{ Living with partner } \\
\hline \multicolumn{4}{|c|}{ Infectious, endocrine, chronic diseases and others } & 238 & 3030 & 106 & & 1093 \\
\hline \multicolumn{4}{|l|}{ Cancer and tumours } & 876 & 3258 & 437 & & 1010 \\
\hline \multicolumn{4}{|c|}{ Diseases of the circulatory system } & 331 & 2504 & 78 & & 1030 \\
\hline \multicolumn{4}{|c|}{ Mental diseases, suicides, accidents and external causes } & 78 & 276 & 20 & & 111 \\
\hline \multicolumn{9}{|c|}{ Living with others, no partner } \\
\hline \multicolumn{4}{|c|}{ Infectious, endocrine, chronic diseases and others } & 133 & 1004 & 60 & & 2269 \\
\hline \multicolumn{4}{|l|}{ Cancer and tumours } & 207 & 565 & 164 & & 892 \\
\hline \multicolumn{4}{|c|}{ Diseases of the circulatory system } & 92 & 834 & 37 & & 2199 \\
\hline \multicolumn{4}{|c|}{ Mental diseases, suicides, accidents and external causes } & 45 & 76 & 15 & & 178 \\
\hline \multicolumn{9}{|l|}{ Living alone } \\
\hline \multicolumn{4}{|c|}{ Infectious, endocrine and chronic diseases } & 73 & 611 & 18 & & 1082 \\
\hline \multicolumn{4}{|l|}{ Cancer and tumours } & 104 & 565 & 59 & & 720 \\
\hline \multicolumn{4}{|c|}{ Diseases of the circulatory system } & 72 & 587 & 28 & & 1331 \\
\hline \multicolumn{4}{|c|}{ Mental diseases, suicides, accidents and external causes } & 26 & 79 & 9 & & 126 \\
\hline \multirow[b]{2}{*}{ Mortality rates } & \multicolumn{4}{|l|}{ Men } & \multicolumn{4}{|c|}{ Women } \\
\hline & $45-64$ & $95 \% \mathrm{Cl}$ & $65+$ & $95 \% \mathrm{Cl}$ & $45-64$ & $95 \% \mathrm{Cl}$ & $65+$ & $95 \% \mathrm{Cl}$ \\
\hline \multicolumn{9}{|l|}{ Living with partner } \\
\hline $\begin{array}{l}\text { Infectious, endocrine, } \\
\text { chronic diseases and } \\
\text { others }\end{array}$ & 0.54 & 0.48 to 0.61 & 9.79 & 9.45 to 10.14 & 0.24 & 0.2 to 0.29 & 4.35 & 4.09 to 4.6 \\
\hline Cancer and tumours & 2 & 1.87 to 2.14 & 10.53 & 10.17 to 10.89 & 1 & 0.91 to 1.09 & 4.02 & 3.77 to 4.26 \\
\hline $\begin{array}{l}\text { Diseases of the circulatory } \\
\text { system }\end{array}$ & 0.76 & 0.68 to 0.84 & 8.09 & 7.78 to 8.41 & 0.18 & 0.14 to 0.22 & 4.1 & 3.85 to 4.35 \\
\hline $\begin{array}{l}\text { Mental diseases, suicides, } \\
\text { accidents and external } \\
\text { causes }\end{array}$ & 0.18 & 0.14 to 0.22 & 0.89 & 0.79 to 1 & 0.05 & 0.03 to 0.07 & 0.44 & 0.36 to 0.52 \\
\hline
\end{tabular}

\section{Living with others, no partner}

\begin{tabular}{|c|c|c|c|c|c|c|c|c|}
\hline $\begin{array}{l}\text { Infectious, endocrine, } \\
\text { chronic diseases and } \\
\text { others }\end{array}$ & 1.42 & 1.18 to 1.66 & 22.15 & 20.8 to 23.51 & 0.54 & 0.4 to 0.67 & 19.26 & 18.48 to 20.05 \\
\hline Cancer and tumours & 2.2 & 1.9 to 2.5 & 12.47 & 11.44 to 13.49 & 1.47 & 1.24 to 1.69 & 7.57 & 7.08 to 8.07 \\
\hline $\begin{array}{l}\text { Diseases of the circulatory } \\
\text { system }\end{array}$ & 0.98 & 0.78 to 1.18 & 18.4 & 17.16 to 19.64 & 0.33 & 0.22 to 0.44 & 18.67 & 17.9 to 19.44 \\
\hline $\begin{array}{l}\text { Mental diseases, suicides, } \\
\text { accidents and external } \\
\text { causes }\end{array}$ & 0.48 & 0.34 to 0.62 & 1.68 & 1.3 to 2.05 & 0.13 & 0.07 to 0.2 & 1.51 & 1.29 to 1.73 \\
\hline \multicolumn{9}{|l|}{ Living alone } \\
\hline $\begin{array}{l}\text { Infectious, endocrine and } \\
\text { chronic diseases }\end{array}$ & 1.5 & 1.16 to 1.85 & 12.91 & 11.89 to 13.93 & 0.43 & 0.23 to 0.63 & 8.52 & 8.02 to 9.03 \\
\hline Cancer and tumours & 2.14 & 1.73 to 2.55 & 11.94 & 10.96 to 12.91 & 1.42 & 1.05 to 1.78 & 5.67 & 5.26 to 6.09 \\
\hline $\begin{array}{l}\text { Diseases of the circulatory } \\
\text { system }\end{array}$ & 1.48 & 1.14 to 1.82 & 12.4 & 11.4 to 13.4 & 0.67 & 0.42 to 0.92 & 10.49 & 9.93 to 11.05 \\
\hline $\begin{array}{l}\text { Mental diseases, suicides, } \\
\text { accidents and external } \\
\text { causes }\end{array}$ & 0.53 & 0.33 to 0.74 & 1.67 & 1.3 to 2.04 & 0.22 & 0.07 to 0.36 & 0.99 & 0.82 to 1.17 \\
\hline
\end{tabular}


Table 3 Continued

\begin{tabular}{|c|c|c|c|c|c|c|c|c|}
\hline \multirow[b]{2}{*}{ Realtive mortality } & \multicolumn{4}{|l|}{ Men } & \multicolumn{4}{|c|}{ Women } \\
\hline & $45-64$ & $95 \% \mathrm{Cl}$ & $65+$ & $95 \% \mathrm{Cl}$ & $45-64$ & $95 \% \mathrm{Cl}$ & $65+$ & $95 \% \mathrm{Cl}$ \\
\hline \multicolumn{9}{|c|}{ Living with others, no partner/living with partner } \\
\hline $\begin{array}{l}\text { Infectious, endocrine, chronic } \\
\text { diseases and others }\end{array}$ & 2.6 & 2.09 to 3.23 & 2.26 & 2.1 to 2.43 & 2.22 & 1.61 to 3.04 & 4.43 & 4.12 to 4.76 \\
\hline Cancer and tumours & 1.1 & 0.94 to 1.28 & 1.18 & 1.08 to 1.29 & 1.47 & 1.23 to 1.76 & 1.89 & 1.72 to 2.06 \\
\hline $\begin{array}{l}\text { Diseases of the circulatory } \\
\text { system }\end{array}$ & 1.29 & 1.02 to 1.63 & 2.27 & 2.1 to 2.46 & 1.86 & 1.26 to 2.75 & 4.56 & 4.23 to 4.91 \\
\hline $\begin{array}{l}\text { Mental diseases, suicides, } \\
\text { accidents and external causes }\end{array}$ & 2.69 & 1.82 to 3.92 & 1.88 & 1.44 to 2.43 & 2.94 & 1.5 to 5.73 & 3.42 & 2.7 to 4.34 \\
\hline \multicolumn{9}{|l|}{ Living alone/living with partner } \\
\hline $\begin{array}{l}\text { Infectious, endocrine, chronic } \\
\text { diseases and others }\end{array}$ & 2.76 & 2.09 to 3.6 & 1.32 & 1.21 to 1.44 & 1.78 & 1.08 to 2.94 & 1.96 & 1.8 to 2.13 \\
\hline Cancer and tumours & 1.07 & 0.86 to 1.31 & 1.13 & 1.03 to 1.24 & 1.42 & 1.08 to 1.86 & 1.41 & 1.28 to 1.55 \\
\hline $\begin{array}{l}\text { Diseases of the circulatory } \\
\text { system }\end{array}$ & 1.95 & 1.49 to 2.53 & 1.53 & 1.4 to 1.68 & 3.77 & 2.45 to 5.8 & 2.56 & 2.36 to 2.78 \\
\hline $\begin{array}{l}\text { Mental diseases, suicides, } \\
\text { accidents and external causes }\end{array}$ & 2.99 & 1.84 to 4.72 & 1.87 & 1.44 to 2.41 & 4.72 & 2.15 to 10.37 & 2.25 & 1.74 to 2.9 \\
\hline
\end{tabular}

picture changes substantially. Contrary to what occurred among mature adults, the situation of elderly people living with others is consistently worse than for those living alone. The sole exception to this are deaths due to falls and mental problems among men. This is strong observational evidence that people living with others at this age have substantially poorer baseline health than those living alone, itself the result of the selection effects mentioned earlier.

There is little research on the subject of excess mortality by residential status in the developed world. Most approaches to mortality make use of marital status though, as shown here, the effect of living alone exists net of the effect of marriage or partner status. The results presented here closely mirror those found for Belgium, ${ }^{31}$ both with respect to the levels of excess mortality as people age and because men make the change after about 75 and women after about 65 . They also suggest that this pattern may be widespread and not limited to Spain (or to Belgium). Unfortunately, the Belgian study does not present results for cause of death, thus limiting comparisons.

The Finnish ${ }^{24}$ and Danish ${ }^{25}$ cases yield somewhat different results. Much as happens in Spain, the excess mortality of persons living alone and those living with others, in comparison to those with spouses, decreases with age. Unlike Spain, however, in Finland mature adults living alone are more likely to die than people in any other residential situation and levels of differential mortality are greater, especially among men. In old age, excess mortality for those living alone disappears in Spain, but not in Finland or Denmark. While excess mortality for those living with others persists in the three countries, it is considerably higher among Finish and Danish men.

This suggests that other factors may be in play related to the role of the family and the readiness of family members to care for kin with poor health. ${ }^{46}$ The threshold of poor health required for moving from living alone into living with others may be higher in Finland and Denmark than in Spain, leading to much higher levels of differential mortality for solo dwellers in Nordic societies relative to people living with partners. In individualistic societies like Finland or Denmark, the value placed on solo living may be higher than in Spain, leading to lower levels of active family intervention as people's baseline health declines and a greater willingness in Nordic countries for people to continue living alone even with very poor health. The role of institutional interventions in Nordic countries designed to help people in very poor health continue to live alone may also be relevant. ${ }^{8}$

\section{LIMITATIONS}

Despite the ample sample used in this study, due to its observational population-based research design, only statistical associations are observed and hence strong causal claims are not strictly proven. Despite stratifying the sample (by sex and age) and controlling for several possible confounders (educational attainment, size of municipality and migratory status), the possibility always exists that unmeasured exposures could influence the outcome if it were possible to take them into the account in the regression models. ${ }^{47}$ Moreover, our analysis of causes of death is mainly illustrative and exploratory because the small number of deaths in some categories precludes us from making robust statistical inferences. Despite these words of caution, however, populationbased research has traditionally contributed much to our understanding of health and ageing in modern society.

\section{CONCLUSIONS}

This paper contributes to clarifying the complex interrelation between health status, residential options and 

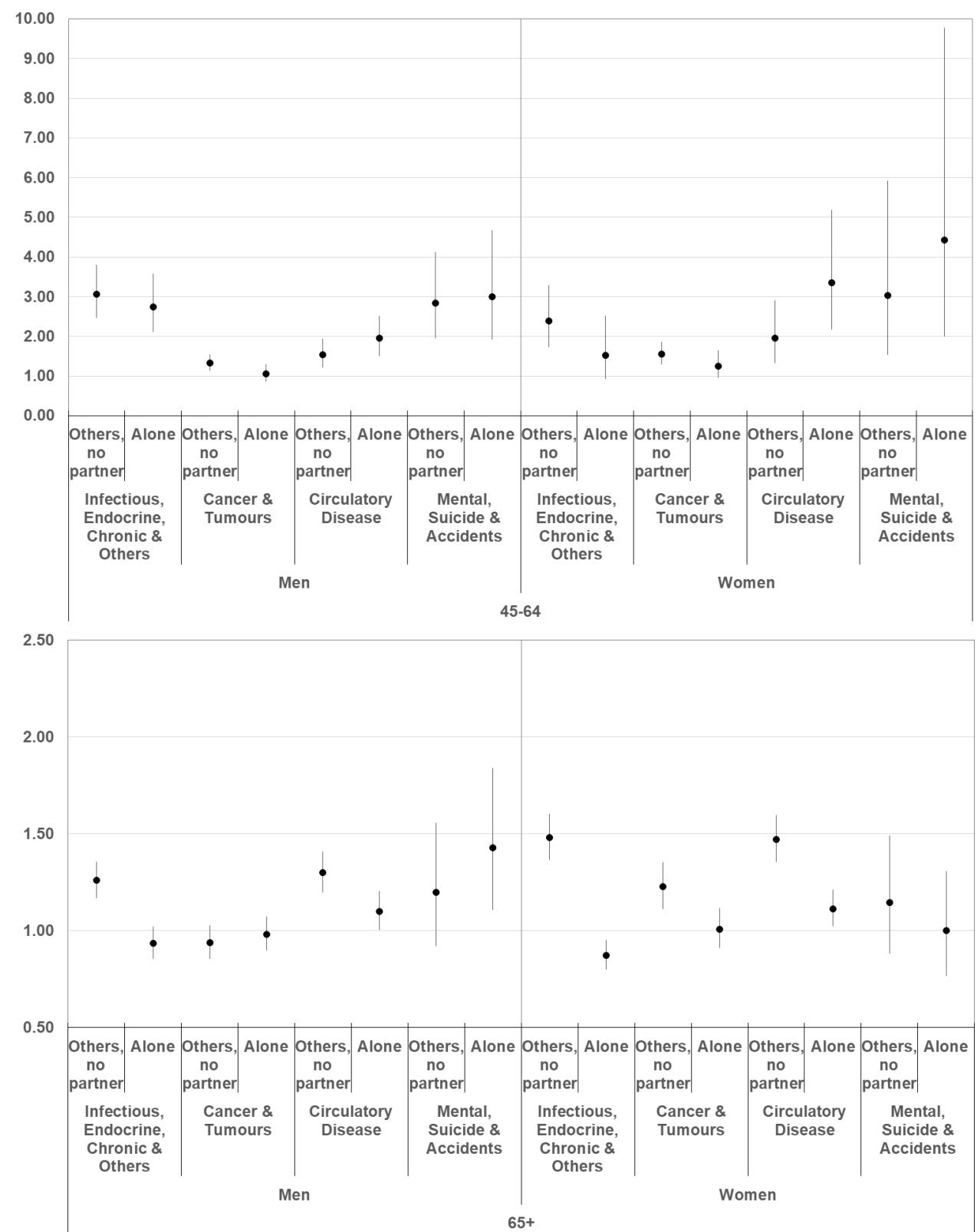

Figure 2 Mortality rate ratios (RR) (living with partner, living with others, living alone) for four groups of cause of death and two broad age groups adjusted by age, educational attainment, size of municipality and migratory status. Reference category $(R R=1)$ is for people living with partners.

mortality with a large data set based on the Spanish population. Its value added is derived from the statistical analysis of a large national data set that points to: (i) the existence of both direct effects of living arrangements on mortality and health-related selection effects on differential living arrangements; (ii) the changing importance of both these effects over the life-cycle, with direct impacts of living arrangements on mortality prevailing among mature adults, and health-related selection effects prevailing among the elderly; and (iii) differential strengths of these effects in different national contexts (Spain or Belgium compared with Nordic countries). These findings provide a crucial framework that helps explain the often ambiguous and unclear results that the pertinent literature has often shown when looking at the implications of residential gradients for mortality.

Contributors MR and DR have contributed equally to the design of the study, the exploitation and analysis of data and the writing of the manuscript. Both authors read and approved the final manuscript.

Funding This work was supported by the Spanish Ministerio de Ciencia, Innovación y Universidades (RTI2018-098455-B-C21) and by Programa de actividades de I+D en Ciencias Sociales y Humanidades, Comunidad de Madrid (S2015/HUM-3321).

Competing interests None declared.

Patient consent for publication Not required.

Provenance and peer review Not commissioned; externally peer reviewed.

Data availability statement No data are available. The linked data used in this study are the result of an ad hoc request to Spanish National Statistical Office 
(Instituto Nacional de Estadistica, INE). We are strictly forbidden from giving them to unauthorised people. Obviously, everyone can ask Spanish INE for the same linked data set and reply our research. Computing code is available upon request to the corresponding author.

Open access This is an open access article distributed in accordance with the Creative Commons Attribution Non Commercial (CC BY-NC 4.0) license, which permits others to distribute, remix, adapt, build upon this work non-commercially, and license their derivative works on different terms, provided the original work is properly cited, appropriate credit is given, any changes made indicated, and the use is non-commercial. See: http://creativecommons.org/licenses/by-nc/4.0/.

\section{ORCID iDs}

Miguel Requena http://orcid.org/0000-0002-4490-6029

David Reher http://orcid.org/0000-0001-5648-0961

\section{REFERENCES}

1 Agree EM. Demography of aging and the family. In: Hayward MD, Majmundar MK, eds. Future directions for the demography of aging, 2018: 159-86.

2 Palloni A. Living arrangements of older persons. in: United nations. living arrangements of older persons: critical issues and policy responses. New York: Population Bulletin of the United Nations, Special Issue Nos. 42/43, 2001: 54-110.

3 United Nations. Living arrangements of older persons around the world. New York: Department of Economic and Social Affairs, Population Division, 2005.

4 Reher D, Requena M. Elderly women living alone in Spain: the importance of having children. Eur J Ageing 2017;14:311-22.

5 Reher D, Requena M. Living alone in later life: a global perspective. Popul Dev Rev 2018:44:427-54.

6 Vespa J, Lewis JM, Kreider RM. America's Families and Living Arrangements: 2012. Current Population Reports P20-570. United States Census Bureau, 2013. Available: https: //www.census.gov/ prod/2013pubs/p20-570.pdf

7 Fokkema T, Liefbroer AC. Trends in living arrangements in Europe: convergence or divergence? Demogr Res 2008;19:1351-418.

8 Padyab M, Reher D, Requena M, et al. Going it alone in later life: a comparative analysis of elderly women in Sweden and Spain. J Fam Issues 2019;40:1038-64.

9 Gove WR. Sex, marital status, and mortality. AJS 1973;79:45-67.

10 Hu YR, Goldman N. Mortality differentials by marital status: an international comparison. Demography 1990;27:233-50.

11 Manzoli L, Villari P, M Pirone G, et al. Marital status and mortality in the elderly: a systematic review and meta-analysis. Soc Sci Med 2007;64:77-94.

12 Rendall MS, Weden MM, Favreault MM, et al. The protective effect of marriage for survival: a review and update. Demography 2011;48:481-506.

13 Robards J, Evandrou M, Falkingham J, et al. Marital status, health and mortality. Maturitas 2012;73:295-9.

14 Burgoa M. Mortality. mortality by cause of death and marital status in Spain. Eur J Public Health 1998;8:37-42.

15 Johnson NJ, Backlund E, Sorlie PD, et al. Marital status and mortality: the National longitudinal mortality study. Ann Epidemiol 2000;10:224-38.

16 Drefahl S. Do the married really live longer? the role of cohabitation and socioeconomic status. J Marriage Fam 2012;74:462-75.

17 Hemstrom O. Is marriage dissolution linked to differences in mortality risks for men and women? J Marriage Fam 1996;58:366-78.

18 Williams K, Umberson D, Status M. Marital status, marital transitions, and health: a gendered life course perspective. J Health Soc Behav 2004;45:81-98.

19 Sbarra DA, Law RW, Portley RM. Divorce and death: a meta-analysis and research agenda for clinical, social, and health psychology. Perspect Psychol Sci 2011;6:454-74.

20 Berntsen KN, Kravdal O. The relationship between mortality and time since divorce, widowhood or remarriage in Norway. Soc Sci Med 2012;75:2267-74.

21 Bourassa KJ, Ruiz JM, Sbarra DA. Smoking and physical activity explain the increased mortality risk following marital separation and divorce: evidence from the English longitudinal study of ageing. Ann Behav Med 2019;53:255-66.

22 Holt-Lunstad J, Smith TB, Layton JB. Social relationships and mortality risk: a meta-analytic review. PLoS Med 2010;7:e1000316.

23 Lund R, Due P, Modvig J, et al. Cohabitation and marital status as predictors of mortality--an eight year follow-up study. Soc Sci Med 2002;55:673-9.

24 Koskinen S, Joutsenniemi K, Martelin T, et al. Mortality differences according to living arrangements. Int J Epidemiol 2007;36:1255-64.

25 Frisch M, Simonsen J. Marriage, cohabitation and mortality in Denmark: national cohort study of 6.5 million persons followed for up to three decades (1982-2011). Int J Epidemiol 2013;42:559-78.

26 Pimouguet C, Rizzuto D, Schön P, et al. Impact of living alone on institutionalization and mortality: a population-based longitudinal study. Eur J Public Health 2016;26:182-7.

27 Kandler $\mathrm{U}$, Meisinger $\mathrm{C}$, Baumert $\mathrm{J}$, et al. Living alone is a risk factor for mortality in men but not women from the general population: a prospective cohort study. BMC Public Health 2007;7:335.

28 Scafato E, Galluzzo L, Gandin C, et al. Marital and cohabitation status as predictors of mortality: a 10-year follow-up of an Italian elderly cohort. Soc Sci Med 2008;67:1456-64.

29 Li LW, Zhang J, Liang J. Health among the oldest-old in China: which living arrangements make a difference? Soc Sci Med 2009;68:220-7.

30 Staehelin K, Schindler C, Spoerri A, et al. Marital status, living arrangement and mortality: does the association vary by gender? $J$ Epidemiol Community Health 2012;66:e22.

31 Poulain M, Dal L, Herm A. Mortality risk by living arrangements for the elderly Belgian population. Quetelet Journal 2016;4:29-56.

32 Jensen MT, Marott JL, Holtermann A, et al. Living alone is associated with all-cause and cardiovascular mortality: 32 years of follow-up in the Copenhagen male study. Eur Heart J Qual Care Clin Outcomes 2019;5:208-17.

33 Kilpi $\mathrm{F}$, Konttinen $\mathrm{H}$, Silventoinen $\mathrm{K}$, et al. Living arrangements as determinants of myocardial infarction incidence and survival: a prospective register study of over 300,000 Finnish men and women. Soc Sci Med 2015;133:93-100.

34 Martikainen $\mathrm{P}$, Nihtilä E, Moustgaard $\mathrm{H}$. The effects of socioeconomic status and health on transitions in living arrangements and mortality: a longitudinal analysis of elderly Finnish men and women from 1997 to 2002. J Gerontol B Psychol Sci Soc Sci 2008;63:S99-109.

$35 \mathrm{Fu} \mathrm{H}$. \& Goldman N. Incorporating health into models of marriage choice: Demographic and sociological perspectives. J Marriage Fam 1996;58:740-58.

36 lliffe S, Tai SS, Haines A, et al. Are elderly people living alone an at risk group? BMJ 1992;305:1001-4

37 Michael YL, Berkman LF, Colditz GA, et al. Living arrangements, social integration, and change in functional health status. $A m \mathrm{~J}$ Epidemiol 2001;153:123-31.

38 Kharicha K, Iliffe S, Harari D, et al. Health risk appraisal in older people 1: are older people living alone an "at-risk" group? Br J Gen Pract 2007;57:271-6.

39 Agrawal S. Effect of living arrangement on the health status of elderly in India. Asian Popul Stud 2012;8:87-101.

40 Cheung Y. Can marital selection explain the differences in health between married and divorced people? from a longitudinal study of a British birth cohort. Public Health 1998;112:113-7.

41 Murray JE. Marital protection and marital selection: evidence from a historical-prospective sample of American men. Demography 2000;37:511-21.

42 Espinosa J, Evans WN. Heightened mortality after the death of a spouse: marriage protection or marriage selection? J Health Econ 2008;27:1326-42.

43 Franke S, Kulu H. Mortality differences by partnership status in England and Wales: the effect of living arrangements or health selection? Eur J Popul 2018;34:87-118.

44 Brown JW, Liang J, Krause N, et al. Transitions in living arrangements among elders in Japan: does health make a difference? J Gerontol B Psychol Sci Soc Sci 2002;57:S209-20.

45 Sarma S, Hawley G, Basu K. Transitions in living arrangements of Canadian seniors: findings from the NPHS longitudinal data. Soc Sci Med 2009;68:1106-13.

46 Reher DS. Family ties in Western Europe: persistent contrasts. Popul Dev Rev 1998;24:203-34.

47 Imbens GW, Rubin DB. Causal inference for statistics, social, and biomedical sciences: an introduction. Cambridge: Cambridge University Press, 2015. 